\title{
115
}

\section{ANDAMENTO DELLA PREVALENZA DEL GENOTIPO 4 DI HCV IN CALABRIA}

Barreca G.S.', Quirino A.', Capicotto R.', Lamberti A.G.', Di Cello C. ', De Rosa M. ${ }^{2}$, Silva A.M.', Giraldi C. ${ }^{3}$, Greco F. ${ }^{3}$ Liberto M.C.', Focà A.'

Cattedra di Microbiologia', Università "Magna Græcia" di Catanzaro;

Laboratorio di Virologia², A. O. B.M.M. di Reggio Calabria;

Unità Operativa di Virologia ${ }^{3}$, A. O. di Cosenza

Introduzione. Il genotipo 4 di HCV ha una maggiore diffusione in Egitto, Medio Oriente (Arabia Saudita, Bahrein, Yemen, Iran) e in Africa Centrale. Scopo del presente studio è stato quello di valutare variazioni nella prevalenza del genotipo 4 del virus dell'Epatite C in Calabria nel periodo compreso tra Marzo 2001 e Maggio 2005.

Metodi. L'RNA virale veniva estratto da campioni di siero provenienti da pazienti anti HCV positivi, rivelato mediante RT-PCR (Cobas Amplicor HCV, Roche) e genotipizzato mediante tecnica di ibridazione inversa su supporto solido (Versant HCVgenotipo LiPA, Bayer). Dal 2003 presso l'A.O. di Cosenza la genotipizzazione veniva effettuata tramite sequenziamento del genoma virale (Trugene $\mathrm{HCV} 5$ ' $\mathrm{NC}$ genotyping Kit, Bayer).

Risultati. Nel periodo considerato, su un totale di 2981 pazienti anti HCV positivi, la percentuale di genotipo 4 riscontrata è stata del 5.7\% (172 pazienti) rispetto al 4.5\% di una precedente indagine effettuata (da Gennaio 1997 a Febbraio 2001), con un incremento del 1.2\%. In particolare nell'area di Reggio Calabria (A.O. Bianchi-MelacrinoMorelli, RC) su un totale di 345 pazienti sono stati rivelati 11 genotipi 4 (3.2\%), con un decremento del 5.2\%; nel territorio cosentino (A.O. di Cosenza, CS) su 1577 genotipi 95 appartenevano al tipo 4 (6.0\%), con un incremento del 1.7\%; in provincia di Catanzaro (Policlinico Universitario "Mater Domini", CZ) i genotipi 4 erano 66 su 1059 pazienti testati, con un aumento, rispetto al precedente periodo, del $2.4 \%$.

Conclusioni. E' stato messo in evidenza come il tipo 4 sia tra i genotipi presenti e che circolano più frequentemente sul territorio calabrese dopo i genotipi $1 \mathrm{~b}, 2 \mathrm{a} / 2 \mathrm{c}$ e 3 . Inoltre, pur essendo tale genotipo diffuso in tutta la nostra regione, sono state osservate ristrette zone in cui si è registrata una più alta incidenza (territorio crotonese, sibaritide). 